\title{
Lothar Dunsch (Feb. 14, 1948-Nov. 28, 2013)
}

\section{Peter Gründler}

Published online: 15 March 2014

(C) Springer-Verlag Berlin Heidelberg 2014

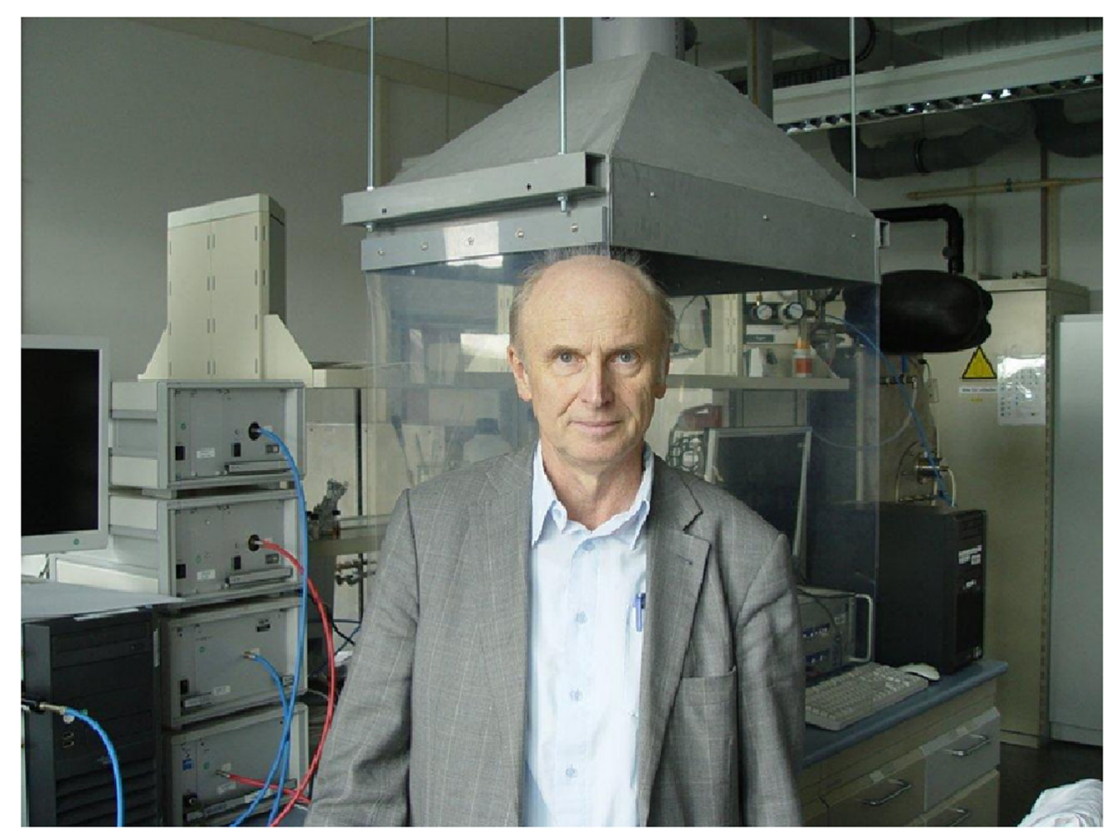

The death has been announced at the age of 65 of Professor Lothar Dunsch, a prominent member of the community of electrochemists, on 28 November 2013 in Dresden. For some months Professor Dunsch had been seriously ill, so his death was not totally unexpected. Nevertheless, his passing was a grave shock to the academic community. Those who knew him well mourn the loss not only of an outstanding academic and scholar but also of a unique personality. What was the secret of this outstanding man?

Databases show that Lothar Dunsch authored 367 learned publications, not to mention numerous patents and nearly one dozen books, among them biographies and a history of elec-

Electronic supplementary material The online version of this article (doi:10.1007/s10008-014-2434-y) contains supplementary material, which is available to authorized users.

\section{P. Gründler $(\square)$}

Hallwachsstraße 5, 01069 Dresden, Germany

e-mail: gruendler.dresden@freenet.de trochemistry. The number of papers is certainly impressive, but not exceptional for a professor of his international standing. A closer look, however, reveals the uneven pattern of his productivity. Between 1973 and 1990, Dunsch published only 22 papers; between 1991 and 2013, however, with only a small group of co-workers, he published a total of 344 papers - an almost 16-fold increase in academic production in the second of two similar time intervals. How can this amazing explosion of productivity be explained? How is it possible for a scientist who initially only published locally, to become within the space of 23 years a leading member of the international elite in such a demanding sphere of scientific enterprise?

Lothar Dunsch is an outstanding example of those who refused to bow to the forces of a totalitarian dictationship, and consequently had to abandon hope of a scientific career. However, after the political changes in the former GDR, his chance came and he took it with both hands.

Dunsch received his academic education at the Bergakademie Freiberg, a prominent, well-established educational institution 
classed as a technical university. He completed his undergraduate studies in 1970 with a degree in chemistry (Diplomchemiker). In 1973, he completed his PhD dissertation. Between 1974 and 1978 he was employed as a research scientist in an institute of the former Academy of Sciences of the GDR, working on the electrochemistry of polymers and radiation initiated graft polymerization. Later, in the years between 1978 and 1990, Dunsch worked at the Institute of Polymer Technology in Dresden. Although not in a high-profile position, he nevertheless managed to make a name for himself, becoming a highly respected member of the community of electrochemists in the GDR. He became the leading specialist in the electrochemical application of glassy carbon and undertook much pioneering work with in-situ ESR spectroscopy in electrochemical cells. For many years he was one of the few persons in Germany who were able to offer assistance if the presence of a radical was suspected in a electrochemical reaction.

During this period Dunsch wrote a number of interesting books. Among them was a short, highly accomplished introduction to the fundamentals of electrochemistry which was much ahead of the times [1]. Even today, it is recommended reading for beginners. My first personal contact with Dunsch was when the former publisher of the book approached me for an expert opinion, the book having already received a negative internal review. The author of this review had declined to recommend it for publication on the grounds that it contained what was regarded as an excess of citations from publications in western periodicals. This was clearly a politically motivated recommendation. A short time later, I myself got to know Dunsch personally, and came to respect him as a fearless fighter for fairness and justice, not limited to himself alone. The book did subsequently get published and was very well received. Lothar Dunsch was an acknowledged expert on the history of chemistry. Very early on in his career he won acclaim not only for his lectures on historical and general topics, but also for his numerous, highly intelligent interventions in discussions at professional conferences.

For many years Dunsch was obliged to work in subordinate positions. This was the price he had to pay for a degree of independence working under a strict totalitarian regime. At that time in the GDR, not to be a member of the "Party" meant not to be allowed to go to international conferences in western countries, and never to be appointed as professor at a university. It also meant not to receive an allocation of research students, but to work more or less alone. This explains the small number of publications in his period of work before the collapse of theGDR. A further consequence of his subordinate, non-party position was that Dunsch had to accept that it was usually his director and not he himself who presented and received the acolades for the results of his scientific research. It has to be said, however, that Dunsch benefited from having, in the figure of Professor Rätsch, a benevolent institutional head. Colleagues sometimes questioned among themselves how, in an institute where electrochemistry was not at the centre of academic interest, Dunsch could conduct so much valuable electrochemical research. This was possible only because of the protection afforded by Professor Rätzsch who shielded many of his other colleagues too from adversity.

In 1989, the year of our peaceful revolution, everything changed, and people looked to individuals like Dunsch for inspiration and guidance. He took an active part in the revolutionary events, becoming one of the founding members of the first anti- regime organisation, "Neues Forum" in Dresden. Later he put much effort into his political activities, being elected to Dresden's first democratic city parliament. It was at this time that he was able to realise one of his dreams, the foundation of his own publishing house, the Hellerau-Verlag, where he published many books by lesser-known authors. He was an enthusiastic editor and also re-published a number of scientific classics. To this day it is difficult to believe how he managed to accomplish so much in the years that followed.

In 1992, after a period as visiting professor at the Heyrovsky Institute in Prague, Dunsch returned to Dresden to head up the Department of Electrochemistry and Conducting Polymers at the Leibniz Institute of Solid State and Materials Science. He established a variety of highly successful research projects, also successfully promoting and organizing numerous international academic conferences, workshops and summer schools. He was honorary professor at the Technical University of Dresden and established a large number of joint international projects with universities and research institutes in countries beyond the German borders, including the USA, Italy, the Czech Republic, Slovakia and Japan.

From 1992 on, Dunsch's main research interests were the generation of LIGA structures, the electrochemistry of conducting polymers, and above all, the spectroelectrochemistry of fullerenes and similar new carbon molecules. In 2009, he founded the Center for Spectroelectrochemistry. Dunsch earned himself particular acclaim for his favourite research topic, the electrochemistry and spectroelectrochemistry of endohedral fullerenes. This fascinating subject, where metallic atoms, clusters, or molecules are completely surrounded by carbon atoms, brought him international recognition at the highest level. His encyclopedic knowledge of the subject is evidenced in a number of review articles, the last, comprehensive one appearing in May 2013.

Lothar Dunsch is survived by his wife Annette, his children and grandchildren.

\section{References}

1. Dunsch L (1983) Vom Ion zur Elektrode. VEB Verlag für Grundstoffindustrie, Leipzig 